\title{
Stories given by children, when to take it with a pinch of salt?
}

\author{
Warushahennadi J ${ }^{1}$. Hewage Chandanie $\mathrm{G}^{2}$
}

1. Department of Forensic Medicine, Faculty of Medicine, University of Ruhuna, Galle.

2. Department of Psychiatry, Faculty of Medicine, University of Ruhuna, Galle.

*Corresponding author: Tel: 0094-773909525. E-mail address: janakiwh@gmail.com

MLSL. Vol 1. No 3. December. pp 17-19

\begin{abstract}
The history given by a child is very important in child abuse investigations. This is especially relevant in cases of child sexual abuse as in some forms of sexual abuse injuries may be absent. The only evidence to prove the case sometimes is the evidence given by the child. The law presumes that the statements given by the child are true. To what extent can a doctor believe a child's history?

This case report describes a situation where a child gave a history of being kidnapped and in the child's own words, "cared for" twice, by an unknown person. There was a suspicion that the child may have been sexually abused. The child gave a similar detailed history to the judicial medical officer (JMO), police, and the psychiatrist. Based on the information received from the child, various investigatory procedures were initiated by the police.

But the detailed examination of this "victim" by the child psychiatrist revealed that the child was having a significant and very prominent fantasy life of a romantic/sexual nature. It was also detected that the child was not very bright intellectually. It appeared that a big proportion of the story given by the child was coloured by her experiences and fantasies.

This case reveals the importance of suspecting the possibility of fantasy, when an unusual story without supporting evidence is given by a child.
\end{abstract}

Key words: child abuse, fantasy, admissibility, evidence

\section{Introduction}

The investigation of a case of child abuse is initiated with the history obtained from the child in many instances. The history given by the child is taken as a guide for medico legal investigation by the doctor and for criminal investigation by the police and it helps the clinician to judge whether the child's history fits the given situation [1].The child's history plays a very important role especially in cases where there is no medical evidence or laboratory evidence to support sexual abuse.

This is a case where a child gave a story of being taken away by an unknown male which aroused the suspicion of possible abuse, and was later found to be a fantasy. 
Then the girl revealed that on the way to school she met a man and a woman in a van, who promised to gift her a house to live, and had taken her by van to a house where there were several naked foreign women. She claimed that she was given a meal of fried rice and a drink of lemon juice after which she felt sleepy and they helped her by giving a comfortable bed to sleep. When she woke up she was brought back and dropped near the school by the time the school was over. She claimed that the man and woman asked her to tell the mother that it was a teacher who took her to show the house. According to her the incident happened twice. She gave a detailed description of the house, people who were there and the meals she was given. Then the school authorities contacted the police due to a suspicion of child abuse.

Similar detailed description of the incident was given to the JMO and the police repeatedly by the girl. The examination of genitalia revealed no evidence of penetration. She was referred to the child psychiatrist as part of the routine assessment.

The police had started investigations in to the case and done a scene visit of the house where she lived. The house was a partially broken mud hut which was an illegal construction. Police had taken the child along several roads to see if she could identify the house she was taken to.

The girl attended psychiatric assessment with her mother. Mother agreed that they were desperately looking for a better place to live. She also revealed that the food and drink the child claimed to have been served by those who took her away were her favorites. The school attendance was checked and she was found to have $100 \%$ attendance during that particular school term. At the end of the assessment, the mother produced an exercise book with the child's handwriting. As there were "hearts" drawn everywhere in the book, the mother thought it was not a school book. The psychiatrist found seven romantic letters which were addressed to the girl, and sent by seven different males judging from the names of the sender. All were of the girl's handwriting and on confrontation she agreed that she wrote them as if boys were writing to her. There were drawings of a sexual nature in some of her school books as well. At the end of the psychiatric assessment it was concluded that the child's story was a fantasy.

\section{Discussion}

The law presumes that a history given by a child is true. Therefore it is important to evaluate the credibility of the history given by a child. A false history given by a child may lead to unnecessary investigations by the doctors, police and law enforcement personnel and may lead to the conviction of an innocent person and also destroy the family especially when the accused is a parent [6].

Children usually have fantasies; preschoolers have more fantasies [2]. With age their fantasy may reduce, but school going children also have a rich fantasy life. During early adolescence fantasies of romantic and erotic nature appear. Frequency of the occurrence is not clearly known. Most children's fantasies are selflimited. Few reveal them in various ways. Some children colour their stories with their fantasies and experiences. Those who are craving for love and attention are more likely to tell stories coloured by fantasies [3].

Fantasy prone personality (FPP) is a disposition or personality trait in which a person experiences a lifelong extensive and deep involvement in fantasy [3]. An individual with this trait (termed a fantasizer) may have difficulty differentiating between fantasy and reality. A fantasy prone person is reported to spend a large portion of his or her time fantasizing, have vividly intense fantasies, have paranormal experiences, and have intense religious experiences [4]. The fantasies may include dissociation and sexual fantasies. Fantasizers have had a large exposure to fantasy during early childhood $[3,5]$. This overexposure to childhood fantasy has at least three important causes: Parents or caregivers who provided a very structured and imaginative mental and/or play environment, exposure to 
physical and/or sexual abuse, such that fantasizing provides a coping or escape mechanism from the abuse and exposure to severe loneliness and isolation, such that fantasizing provides a coping or escape mechanism from the boredom.

Regarding psychoanalytic interpretations, Sigmund Freud has stated that "unsatisfied wishes are the driving power behind fantasies, every separate fantasy contains the fulfillment of a wish, and unproves an unsatisfactory reality." This shows loneliness and dissatisfaction in life and can result in people creating a fantasy world of happiness in order to fill the void. Young children who once were treated for abuse and had a parent leave created a world of fantasies to escape from reality [1]. It is not a psychiatric illness and there is no treatment or therapy required.

This case report reveals the importance of suspecting the possibility of fantasy when an unusual story without supporting evidence is given by a child. The introduction of psychiatric testimony intended to impeach the child's credibility will be helpful in this type of case where substantial corroboration supporting the charge is lacking. In order to justify the admissibility of mental health evidence, courts should identify specific and legitimate relevance to the complainant's credibility [6]. This should be balanced against the potentially misleading and confusing effect that the information will have on the fact finding procedure. In some states of America a psychiatric evidence of credibility of sexual assault complainants are adopted but no state has adopted a coherent approach that considers mental health as a category [6].

\section{References}

1. Roy Meadow, Jacqualine Mak, Donna Rosenberg, $A B C$ of child's protection. 4th Edition Blackwell publishing 2007 P - 6.

2. Taylor M, Carlson SM, Maring BL, Gerow L, Charley CM. Department of Psychology, University of Oregon, Eugene, OR, USA. mtaylor@uorgon.edu.Pub Med - indexed for Medicine.

3. Lynn, Steven J., and Judith W. Rhue (1988). Fantasy Proneness: Hypnosis, developmental antecedents, and psychopathology. American Psychologist, vol. 43, pages 35 - 44.

4. Merckelbach, H. et al. (2001). The Creative Experiences Questionnaire (CEQ): a brief self-report measure of fantasy proneness. Personality and Individual Differences, vol. 31, 987-995.

5. Rhue, Judith W., and Steven Jay Lynn (1987). "Fantasy Proneness: Developmental Antecedents." Journal of Personality, vol. 55, $121-137$.

6. Cossins, A. (1999) 'Recovered Memories of Child Sexual Abuse: The Science and the Ideology' in J. Breckenridge and L. Laing (eds) in Australian Perspectives on Violence against Women, Allen \& Unwin: Sydney.

\section{Contribution of authors}

Examination of the patient-JW

Opinion- JW, CH

Writing the manuscript $-\mathrm{JW}, \mathrm{CH}$

Revising the manuscript- $\mathrm{CH}$ 